\title{
Campanhas educacionais de prevenção ao HIV no Brasil de 1987 a 2002
}

\author{
Simone M. Wolfgang (UniCarioca) \\ Denise B. Portinari (PUC-Rio) \\ Patricia Castro Ferreira (FIOCRUZ)
}

\section{Resumo}

Este artigo tem como objetivo principal questionar os rumos que a prevenção à Aids no Brasil tomou nos últimos anos. A argumentação será feita através da exposição de seis comerciais de prevenção veiculados pelo programa oficial de HIV/Aids e Hepatites virais do governo brasileiro nas últimas três décadas. Os comerciais aqui apresentados mostram como as mudanças nos discursos, as opções temáticas e as descobertas médicas relacionadas ao tratamento da doença foram determinantes para a manutenção de uma prevenção exclusivamente calcada no discurso imperativo do sexo seguro do tipo chamado aqui de "discurso do risco", em detrimento da informação e da interação com o público visado. Esse questionamento conduz a uma reflexão sobre o papel desempenhado pelo designer na elaboração e na divulgação de campanhas de prevenção ligadas à saúde.

Palavras-Chave: Design gráfico; prevenção a AIDS; HIV.

\begin{abstract}
This article raises some questions about some past developments that occurred in Aids prevention campaigns in Brazil. Towards this end, the article examines six television prevention campaigns that were part of the official government HIV/Aids and viral Hepatitis program over the last three decades. The commercials thus analyzed show how changes in discourse, thematic focus and medical discoveries have determined the more or less permanent election of a prevention strategy that is based exclusively on a safer sex imperative discourse, named here as "risk discourse". The questioning of this paradigm raises the issue of the relatively minor role played until now by design professionals in the decision-making process of creation and diffusion of health-related prevention campaigns.
\end{abstract}

Keywords: Graphic design, AIDS and HIV Prevention.

\section{Introdução}

Este artigo traz um questionamento sobre os rumos tomados pela prevenção à Aids no Brasil nas últimas três décadas. A escolha por esta temática se deu devido à inserção das pesquisadoras no universo da prevenção à Aids através da pesquisa ligada à tese de doutorado intitulada Suposições: como você sabe o que sabe sobre? Prevenção, design e sexo, desenvolvida no Laboratório de Representação Sensível, do Departamento de Artes \& Design da PUC-Rio.

Nossa argumentação é conduzida a partir da apresentação de seis comerciais de televisão veiculados pelo Ministério da Saúde brasileiro, no período de 1987 a 1996. A opção por se trabalhar com as campanhas televisivas se deu, pois, através da observação e análise de conteúdo dessas peças publicitárias. Podem ser vistas, de maneira clara, as mudanças temáticas das campanhas de prevenção ao longo da epidemia. 
As propagandas televisivas do Ministério da Saúde funcionam como uma espécie de interlocutor dos rumos da epidemia. As mudanças ocorridas nas campanhas podem ser notadas a partir dos diferentes discursos e opções temáticas utilizados nas campanhas ano após ano.

As razões para as mudanças temáticas são várias e vão desde um apaziguamento moral que destronou o discurso da morte utilizado nos primeiros anos da prevenção à Aids no Brasil e no mundo, substituindo-o por um discurso ligado a uma sexualidade responsável e saudável, quase sempre em campanhas lúdicas e bem humoradas que propagam discursos de sexo seguro, até as grandes descobertas médicas relacionadas ao tratamento da doença.

Através da apresentação das campanhas e da análise de seu conteúdo discursivo, pode-se pensar em algumas perguntas que funcionam não só como fio condutor dessa argumentação, mas também no ponto de partida para se pensar outras formas para a prevenção como, por exemplo, por que se insiste na utilização das mensagens de sexo seguro como carro chefe da prevenção à Aids? Ou ainda, as campanhas preventivas exercem de fato um papel educativo, ou se limitam a propagar mensagens imperativas que levam a uma conduta comportamental diante da ameaça de um grande problema de saúde pública?

Tendo em vista esses questionamentos, quais seriam as possíveis alternativas para a promoção de uma prevenção ampla e eficaz?

No campo de trabalho que envolve a prevenção e cuidados, a constituição de equipes multidisciplinares, formadas por profissionais oriundos de diversas áreas, tais como designers, cientistas sociais e psicólogos, poderia ser uma maneira de criar campanhas de prevenção diferenciadas, com melhor resposta preventiva por parte da população em geral?

\section{Metodologia}

Para a elaboração deste artigo, foi necessário selecionar algumas peças de prevenção à Aids que contassem bem a história da epidemia para ilustrar as modificações temáticas e teóricas que ocorreram no advento da prevenção ao HIV/Aids no Brasil. Para que essa "história" fosse contada da melhor maneira possível, a escolha das peças se deu no sentido de apresentar campanhas que melhor representassem os diferentes discursos ligados à prevenção à Aids e como eles foram se modificando com o passar dos anos. Todo material utilizado neste artigo foi obtido no site "aidsmediacenter", que funciona como arquivo oficial das campanhas brasileiras.

A análise das peças tem como objetivo levantar as relações existentes entre as mensagens contidas nas peças, a forma de veiculação escolhida e o momento histórico da epidemia em que se inserem.

Além disso, a seleção dos comerciais analisados se deu de maneira a procurar apresentar para o leitor a formação de um imaginário ligado ao HIV/Aids nas diferentes épocas da epidemia, de forma a ilustrar como a concepção das campanhas estava diretamente ligada à condução social da epidemia, ao gerenciamento das informações fornecidas pela mídia e à gestão dos riscos em saúde de maneira geral.

A apresentação das campanhas se dá de maneira a respeitar o tempo histórico de veiculação na TV, começando pela mais antiga veiculada em 1987 até a mais recente em 1996.

\section{Primeiro período do programa nacional de 1987 até 1992}

As primeiras campanhas oficiais de cuidados e prevenção à Aids começaram a ser veiculadas de forma regular apenas no final da primeira metade dos anos de 1980. Pode-se dizer que, naquele momento, elas seguiam 
duas estratégias básicas: a primeira, de caráter mais informativo, cujo conteúdo buscava divulgar o que se sabia sobre as reais formas de contaminação, e a outra, mais "alarmista", ou mais voltada para a intimidação como forma de precaução.

No começo da epidemia, muito se especulava sobre as reais formas de contaminação e quem estaria realmente suscetível à doença. Outra questão preponderante quanto ao conteúdo das campanhas no começo dos anos de 1980 era a clara negociação entre o que deveria ser dito e os tabus ligados ao vírus. Não eram incomuns discussões sobre a validade médica de questões como a testagem universal de doadores de sangue, quando a doença seria, supostamente, restrita aos grupos de risco.

Nos anos 80, as campanhas brasileiras enfatizavam basicamente o caráter mortal da doença e todas as suas conhecidas formas de prevenção, por meio de chavões que viriam a se tornar muito populares como Quem vê cara não vê Aids. Durante os primeiros anos da epidemia, o medo foi a personagem principal das campanhas de prevenção.

A estratégia brasileira de prevenção, na segunda metade dos anos de 1980, baseava-se em medidas pontuais e localizadas principalmente através dos meios de comunicação de massa. Os comerciais de televisão eram escolhidos, porque as autoridades de saúde os consideravam um instrumento de amplo alcance.

Esse meio de veiculação fazia parte de um plano que teria o apoio de ações educativas nos colégios e uma discreta distribuição de mídia impressa. Segundo o Ministério da Saúde, a escolha da publicidade em televisão como principal meio de veiculação no começo da epidemia se deu devido ao caráter expansivo da publicidade televisiva, teoricamente abrangendo grandes massas:

O modelo do comercial de televisão comprovou-se como excelente indutor da compra de bens de consumo, mas não determina com a mesma facilidade a adoção de condutas desejadas, a exemplo do uso da camisinha. Serve, porém, para agendar massivamente o tema e para a transmissão das informações tecnicamente corretas acerca dos modos e atitudes de prevenção. O principal, a mudança de comportamento da população face à expansão do vírus da AIDS, é uma meta mais apropriada a campanhas educativas de longo prazo envolvendo a participação de lideranças e movimentos comunitários. (Brasil, 1999; p. 70)

A primeira campanha de prevenção governamental, intitulada Aids, você precisa saber evitar, foi veiculada no Brasil em 1987. Ela foi seguida pela campanha Aids, pare com isso! que contou com uma série de filmes informativos veiculados durante os anos de 1988 e 1989, pelo Ministério da Saúde, do então governo José Sarney. Ambas trabalhavam com dois tipos de temática: a primeira, informativa, enunciava as possíveis formas de contaminação e apresentava uma a uma as práticas consideradas de risco. A segunda, por sua vez, focava basicamente a questão da desestigmatização do soropositivo, buscando divulgar mensagens de estímulo à convivência entre o soropositivo, seus amigos e familiares. Essa tentativa de desestigmatização foi tema de campanhas de prevenção no mundo todo na segunda metade dos anos de 1980.

Houve uma primeira fase, composta por 19 filmes exibidos de 1988 a 1991. Destinados à população em geral, apresentavam a Aids enfatizando sua letalidade e anunciavam como prevenção, além do uso da camisinha, a redução de parceiros. É um momento em que vigora o conceito de grupos de risco como orientação das políticas voltadas para a epidemia, daí a identificação explícita aos usuários de drogas (viciados, como referido no texto de um vídeo), hemofílicos, homossexuais e prostitutas. (LEMOS, 2006; p. 51).

Abaixo, está um exemplo de propaganda de prevenção veiculada nos anos de 1980 pelo Ministério da Saúde no Brasil. O filme Arlequim inaugurou uma tendência que perdura até hoje: o lançamento de novas campanhas todo ano, sempre na época do carnaval.

Arlequim é uma campanha que apresenta a questão da morte ligada à contaminação pelo HIV de maneira muito marcante. A maquiagem do personagem se confunde com as marcas típicas de um doente de Aids, sarcomas, feridas, perda de peso, etc. É interessante notar, porém, que naquele momento histórico, apesar da morbidez ter sido um ponto forte nas campanhas, a questão informativa era bastante elaborada e sempre trazia em cada campanha todos os possíveis meios de contaminação. 
Tratava-se de prevenção una que procurava dar conta de muitos aspectos, desde o uso das drogas, passando pelo sexo até as transfusões de sangue. Esse dado é muito interessante, pois as campanhas governamentais brasileiras dessa época contavam com um viés informativo que as diferenciava dos programas de prevenção estrangeiros, que continuamente enfatizavam apenas a questão da morte e dos grupos de risco.

\section{Texto do comercial Arlequim - Programa Nacional em DST - Aids (1988)}

Quanto riso, quanta alegria! Este é o lado bom da folia, mas existe uma outra face que não tem nada de iluminada, é a face trágica de uma doença mortal chamada Aids. Ela se transmite pelo sexo, pelas seringas e agulhas contaminadas e até pelas transfusões clandestinas de sangue. A máscara da face não revela quem tem ou quem não tem a doença. Quem vê cara não vê Aids! Faça da camisa de Vênus sua companheira inseparável qualquer que seja o seu parceiro. Exija o teste antiaids, se precisar de sangue. E, se precisar de injeção, use seringas descartáveis, nunca use de outra pessoa. Lembre-se de que a Aids mata sem piedade e está se espalhando por aí. Depende de você interromper este triste cordão. Não permita que este seja o último carnaval da sua vida. Aids, pare com isso!

O filme Arlequim, de 1988, que fazia parte da campanha Quem vê cara não vê Aids, uma série de 4 filmes com duração de 60 segundos. Arlequim foi o primeiro a realizar uma associação com o carnaval, período que depois foi escolhido como data fixa para o lançamento das campanhas de prevenção. Nele, a imagem de um folião vestido de arlequim acompanha uma narração em off e o espectador assiste a uma sequência de degradação. Ao longo de um minuto, o palhaço, único personagem do filme, perde o brilho, a alegria e a saúde e termina em um quarto de hospital debilitado, sob um crucifixo pendurado na parede. A fala menciona uma outra face da folia que não tem nada de iluminada. O tom é ameaçador e produz o apelo emocional. $\mathrm{O}$ slogan quem vê cara não vê Aids é desenvolvido no texto que dispara: - é a face trágica de uma doença mortal, chamada Aids. Lembre-se de que a Aids mata sem piedade. E está se espalhando por aí. (LEMOS, 2006; p. 52).
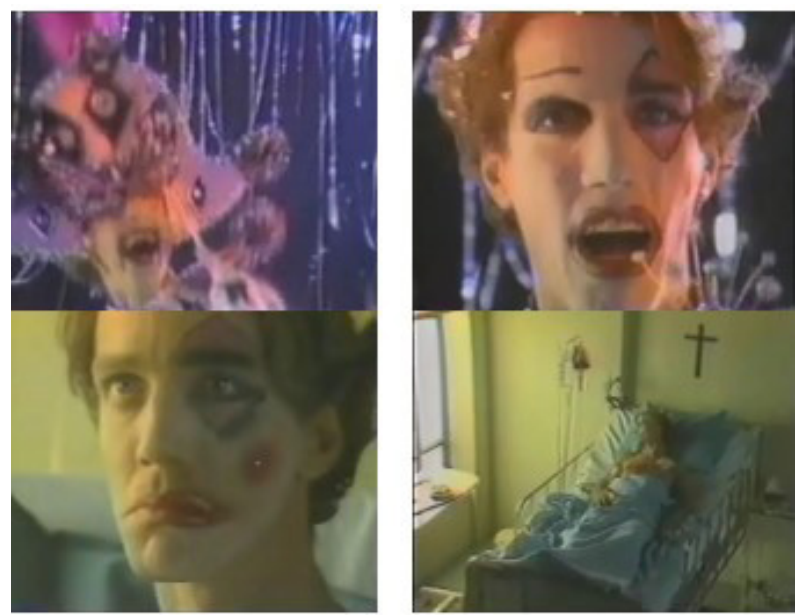

Figura 1: Imagens extraídas do vídeo da propaganda de prevenção “Arlequim” (1987).

\section{A procura pela desestigmatização}

O programa governamental brasileiro de prevenção apresentou uma inovação ao veicular, em 1987, uma propaganda que abordava o tema do preconceito ligado ao paciente de Aids, no comercial intitulado $\mathrm{ca}$ rinho, que fez parte da campanha Aids: você precisa saber evitar. A mensagem contida nessa campanha focava a questão da desestigmatização. Em seus dizeres Aids não se pega convivendo com o doente da Aids. Aids não se pega com afago e com afeto, ela procurava promover uma aproximação com o paciente e uma conscientização sobre as formas de contágio. Em 1987, a epidemia era recente, e a atmosfera de medo ligada a uma doença mortal e sem cura ou tratamento ainda estava muito presente, não era incomum a crença de 
que Aids se transmitia pelo toque ou pelo convívio. Esse tipo de campanha era fundamental para esclarecer a população e diminuir o preconceito com o doente. Todavia, é importante ressaltar que essa temática só foi retomada pela prevenção oficial brasileira em 2006. De todas as propagandas antiaids veiculadas pelo governo entre 1987 e 2006, apenas o comercial carinho abordou a questão da vivência com o vírus HIV e do cuidado com o portador. A temática só foi retomada na campanha do dia mundial de 2006, quando o Ministério da Saúde promoveu a campanha a vida é mais forte do que a Aids, que mostrava soropositivos dando seus depoimentos sobre a rotina ligada à vivência com o vírus no século XXI.

\section{Texto do comercial Carinho - Programa Nacional em DST - Aids (1987):}

De todos os sintomas da Aids, o que causa mais dor é a solidão. Na maioria dos casos, a família e os amigos se afastam do doente da Aids por medo ou preconceito. Aids não se pega convivendo com o doente da Aids. Aids não se pega com afago e com afeto. Enquanto a cura não vem, carinho é o melhor tratamento. Aids - você precisa saber evitar.
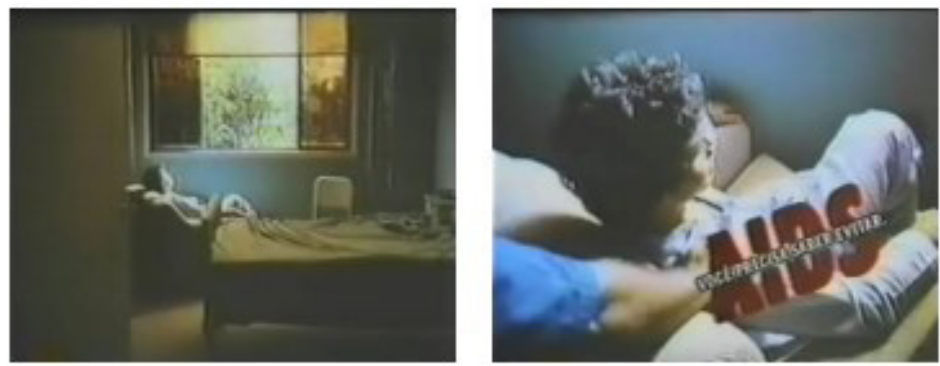

Figura 2: Imagens extraídas do vídeo da propaganda de prevenção “Carinho" (1987).

\section{Um retrocesso}

O terceiro exemplo apresentado aqui, o filme Eu não tenho cura, fez parte de da campanha governamental intitulada Se você não se cuidar, a Aids vai te pegar, veiculada pelo Programa de Conscientização da Aids, criado pelo então presidente Fernando Collor de Mello. Apesar de esse comercial ter sido veiculado em 1991, quando a maioria das entidades de cuidados e combate à Aids já esboçavam uma preocupação maior em não fazer da morte a temática central de suas estratégias de prevenção, esta campanha estava focada somente na questão da ausência de uma cura para a Aids, e para a certeza da sentença de morte ligada a uma possível contaminação, não fornecendo nenhum tipo de informação sobre contágio, riscos, convivência ou qualquer aspecto mais esclarecedor relacionado à prevenção da doença.

Considerada um retrocesso na época, a campanha foi duramente criticada por ONGs e entidades de prevenção independentes, por ser considerada pouco informativa, alarmista e preconceituosa. Apesar de ter sido veiculada alguns anos depois das primeiras campanhas mostradas acima, é importante mostrá-la, uma vez que ela é um exemplo de campanha que tomou a questão da morte como temática central, nuance da prevenção que foi explorada por órgãos oficiais do mundo inteiro durante muito tempo.

Devido aos protestos ligados à veiculação deste comercial, ele ficou pouco tempo no ar. Sobre esse comercial, Herbert de Souza fez um comentário partindo de sua posição de soropositivo relatando sua experiência ao ser surpreendido por essa propaganda.

Assim como todo brasileiro, vejo televisão. Depois de um dia de trabalho intenso, cheguei em casa e liguei a TV para ver os noticiários, quando fui pego de surpresa. Aparecia na tela um jovem que dizia 
ter sido tuberculoso, mas que estava curado. Respirei aliviado. Uma jovem dizia que tinha câncer e que se curou. Fiquei mais animado ainda com o progresso da medicina. Logo entra um jovem, olha para mim e diz: 'Eu tenho Aids e não tenho cura!'... Fiquei parado por um tempo, pensando, com amarga sensação de que alguém me estava puxando para baixo, para a ideia de morte, para o fundo do poço. Custava a crer que fosse uma propaganda promovida pelo Ministério da Saúde, mas era. (SOUZA, 1994; p. 32).

\section{Texto do comercial Se você não se cuidar, a Aids vai te pegar"(1991) - Programa de Cons- cientização da Aids:}

Eu tive tuberculose, eu tive cura. Eu tive câncer, eu tive cura. Eu tive sífilis, eu tive cura. Eu tenho Aids, eu não tenho cura. Narração: nos próximos dias, nos próximos meses, no próximo ano, milhares de pessoas vão pegar Aids e vão morrer. Se você não se cuidar, a Aids vai te pegar. Eu tive tuberculose, eu tive cura. Eu tive câncer, eu tive cura. Eu tive síflis, eu tive cura.
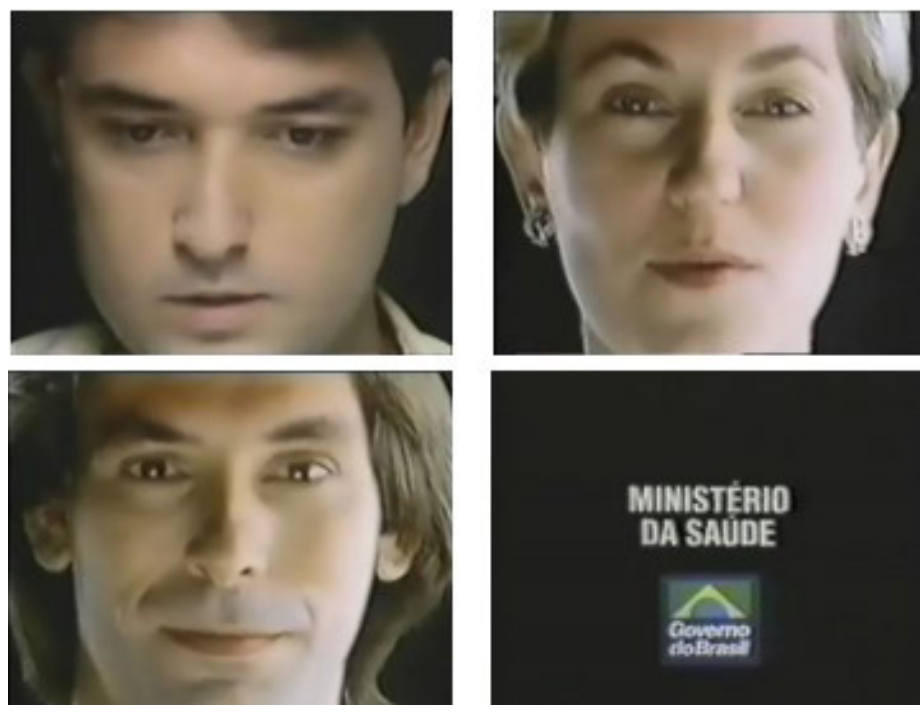

Figura 3: Imagens extraídas do comercial Se você não se cuidar, a Aids vai te pegar (1991)

Utilizar o medo como forma de prevenção promovia uma espécie de silêncio imposto que anulava ou deslocava o foco das informações pertinentes para a promoção de um cuidado mais pontual com relação à prevenção do vírus, além de não levar em conta a posição do soropositivo, bem como a difícil experiência da doença.

\section{Uma prevenção mais lúdica e bem humorada}

No começo da década de 1990, boa parte dos programas de prevenção governamentais do mundo ocidental utilizava uma temática mais lúdica para suas peças de prevenção, desvencilhando-se das primeiras campanhas da década de 1980, em que o caráter mortal da doença parecia mais preponderante. O Brasil não demorou muito a se posicionar de maneira semelhante, e, assim, surgiram as primeiras campanhas da terceira etapa do programa brasileiro, veiculadas a partir de 1993, que se diferenciavam bastante, gráfica e conceitualmente, daquelas apresentadas nos primeiros anos da epidemia. 
Aos poucos, foi abandonado o discurso da morte e também as denominações mais polêmicas como a expressão grupos de risco. No começo dos anos de 1990, a MTV se mostrou pioneira nesse sentido e adotou a expressão comportamento de risco como slogan e jargão para suas campanhas de prevenção de uma maneira geral.

De fato, o conceito é gradativamente substituído pelo de comportamento de risco/categorias de exposição, que, embora em alguma medida problemático, representa um avanço inquestionável na direção da desconstrução do essencialismo dos grupos de risco e de uma maior abertura para pensar o mutante quadro epidemiológico. (BASTOS, 1996; p.135).

Nessa época, então, os discursos relacionados à prevenção mudaram. Abandonou-se, quase que definitivamente, a questão da morte, colocando em evidência a responsabilidade pessoal e irrestrita sobre o cuidado de si, através da vivência de uma sexualidade saudável e responsável através do uso do preservativo masculino, ou seja, as políticas de sexo seguro. Criou-se uma espécie de assinatura, que está presente nas campanhas oficiais de prevenção nacionais de 1993 até os dias atuais (2015): a repetição constante das mensagens do sexo seguro e do uso da camisinha.

O programa oficial brasileiro de prevenção lançou, em 1993, uma nova campanha, cuja linguagem diferiu completamente das campanhas veiculadas nos anos de 1980. Tinha como título o slogan Você tem que aprender a transar com a existência da Aids. Nessa época, o programa oficial brasileiro passou a seguir a tendência vista na prevenção veiculada nos Estados Unidos e na Europa, abandonando as mensagens focadas no caráter mortal da doença e passando a adotar para suas campanhas preceitos amparados em uma sexualidade norteada pelas práticas de sexo seguro. Abaixo, estão imagens de um dos filmes da campanha Você tem que aprender a transar com a existência da Aids, veiculada em 1994.

\section{Transcrição do texto do comercial}

Nem te conto. Quase perdi uma gata. A gente tava sozinho lá em casa, e o clima foi esquentando, esquentando, aí eu lembrei que eu tava sem camisinha. Não vai dar. Mostrei para ela que não era vacilo meu. Narrador: legal numa relação é saber transar a realidade. Sem camisinha, diga não, ou use a imaginação. Se a gente tá junto, mais do que nunca. Narrador: você precisa aprender a transar com a existência da Aids.
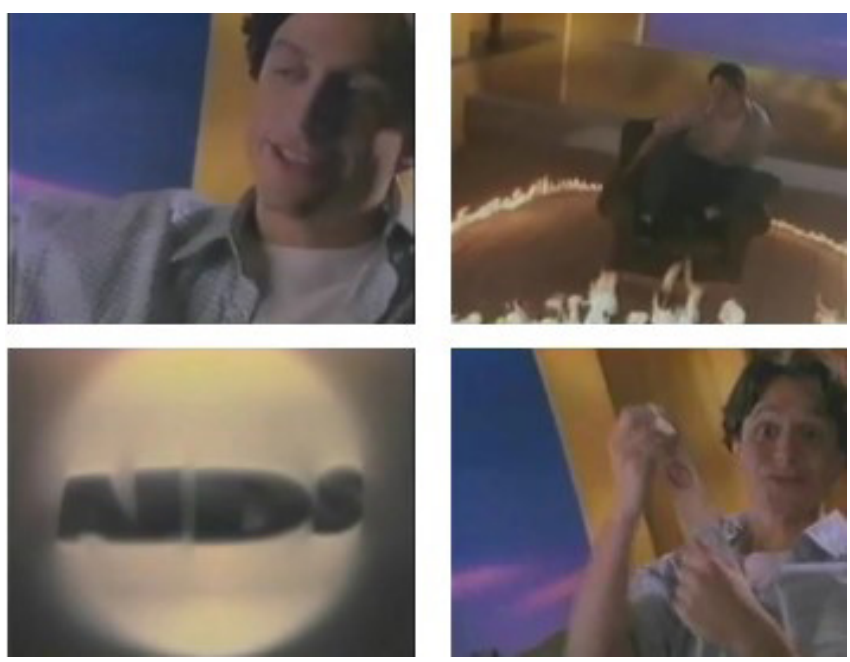

Figura 4: Imagens extraídas do comercial Você tem que aprender a transar com a existência da Aids (1994) 
No que diz respeito à temática principal ligada à prevenção, as mudanças se deram tanto no formato dos apelos, quanto na ampliação de temas e de perspectivas. Duas vertentes ficaram em evidência durante todos esses anos: o discurso do uso da camisinha e do sexo seguro e a ênfase na responsabilidade individual, ou seja, cabe ao indivíduo se proteger através do uso do preservativo masculino em todas as relações sexuais.

As campanhas Quem se ama se cuida e Viva com prazer, viva o sexo seguro, veiculadas nos anos de 1994 e 1995, respectivamente, ilustram bem a nova prevenção brasileira através de um discurso descontraído e com ar jovial, no qual o desfecho é a figura da camisinha e as mensagens de sexo seguro. Nesse momento, podese dizer que a dicotomia camisinha/cuidado pessoal passou a ser a marca da prevenção oficial brasileira de forma determinante e definitiva.

Outro exemplo que ilustra bem a mudança de paradigma das campanhas de prevenção oficiais do governo brasileiro entre os anos de 1980 e 1990 pode ser observado em um trecho da dissertação de Lemos (2006), em que ele mostra o contraponto entre dois anúncios veiculados como campanhas de carnaval. O autor faz uma comparação entre a propaganda Arlequim, de 1987 (Figura 1), e a campanha Desde os tempos mais remotos, de 1995 (Figura 5). No trecho, Lemos ressalta as diferenças temáticas, discursivas e imagéticas entre as duas campanhas em um intervalo de menos de dez anos entre as duas veiculações.

Se Arlequim, de 1987, enfatizava a questão do medo valendo-se do carnaval como período de especial atenção, o anúncio Desde os tempos mais remotos, de 1995, aborda a mesma temática com outro apelo. Nele não se utiliza o tom ameaçador presente em Arlequim. A história da camisinha é contada através de um samba enredo, que é ao mesmo tempo trilha sonora e texto do anúncio. Personagens do carnaval participam do vídeo, como uma porta-bandeira adornada com camisinhas. (...) Voltando à comparação entre este anúncio e Arlequim, é possível observar como o discurso pautado na culpa, no medo, na divulgação de informações sobre como se pega e como não pega Aids, bem como as imagens associadas à doença, à morte, à solidão, cederam espaço a outro que enfatiza a alegria, a coletividade, o prazer moderado (i.e, com o uso da camisinha e consequentemente do autogoverno (afinal, Quem se ama se cuida). (Apud SANTOS, 2002; pp.193,194, in LEMOS, 2006).

\section{Desde os tempos mais remotos}

Transcrição da música: Desde os tempos mais remotos: A camisinha sempre foi um bom programa/ Em Roma e no Antigo Egito/ Ninguém sabia o que levava para a cama/ Marco Antônio também usava/E Cleópatra exigia e apoiava/ Na Idade Média foi igual/Com doença a dar com pau/Ninguém se arriscava/Daí veio o século vinte/ $\mathrm{E}$ a Aids acabou com a brincadeira/Todo mundo tem que ser esperto/ Por que ficar sem camisinha é dar bobeira/ Oi/ Bota a camisinha/ Bota pra valer/ E não dá chance pra esse tal de HIV. (Música e letra: Jamelão).

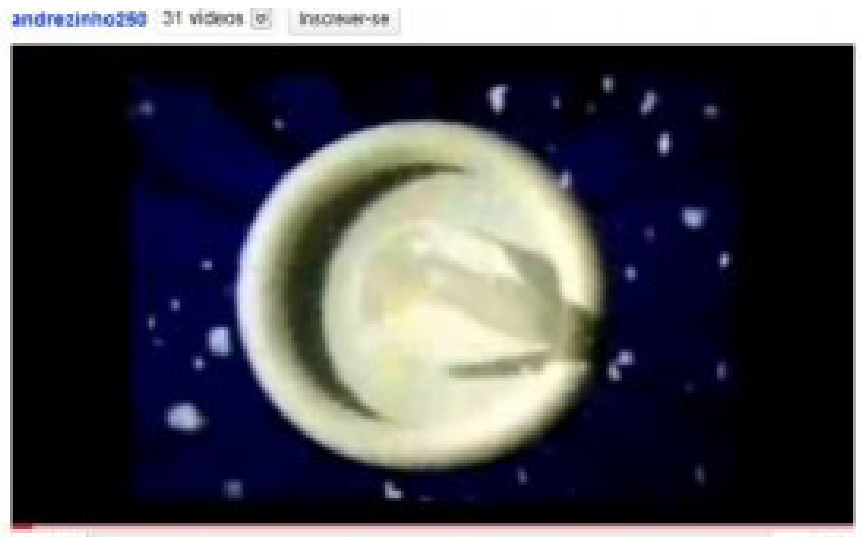

Figura 5a: Imagens extraídas do comercial “Desde os tempos mais remotos” (1995) 


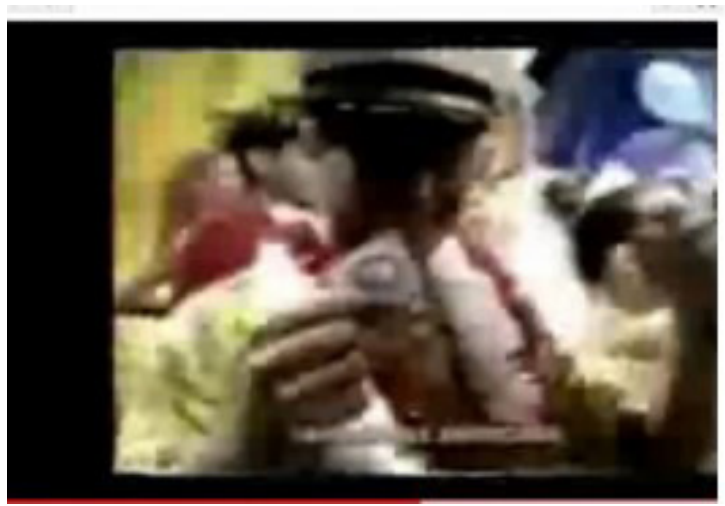

Figura 5b: Imagens extraídas do comercial “Desde os tempos mais remotos” (1995)

\title{
Um coquetel que mudou a doença e sua prevenção
}

Em 1995, chegavam ao mercado os medicamentos antirretrovirais que ofereceriam um grande alívio aos portadores do vírus, combatendo a infecção de forma eficaz, reduzindo drasticamente os índices de mortalidade e, finalmente, possibilitando a vivência com o vírus por muitos anos. Talvez esta diminuição da mortalidade/morbidez ligada à doença tenha ajudado a manter o tom da prevenção oficial brasileira, mantendo o padrão lúdico e bem humorado estabelecido alguns anos antes. Vale ressaltar aqui, porém, que essas campanhas amparadas em aspectos lúdicos e bem humoradas foram aos poucos suprimindo o conteúdo informativo ligado à prevenção. As campanhas, então, passaram a se limitar apenas em propagar a mensagem do uso da camisinha de maneira massiva e repetitiva sem maiores esclarecimentos com relação a formas de contágio, locais de testagem, aconselhamento e afins.

O conteúdo descrito acima pode ser visto na campanha Viva com prazer, viva o sexo seguro, de 1996. A escolha por trazer esse anúncio especificamente se deu porque ele ilustra muito bem a questão lúdica e bem humorada mencionada no parágrafo anterior e também porque essas propagandas foram motivo de polêmica na época. Tratava-se de uma série de seis filmes em que um homem conversava com o próprio pênis, apelidado de Bráulio. Devido a protestos oriundos de entidades religiosas e diferentes setores que consideravam a campanha imprópria, ela foi veiculada por pouco tempo sendo retirada do ar após alguns meses. As críticas à campanha, que ficou conhecida como Bráulio, pouco estavam relacionadas a deficiências na informação preventiva, mas sim as acusações quase sempre apontavam para o fato de a campanha estar focada no pênis e não na doença. Sobre isso Marinho (2006) afirma:

\begin{abstract}
A Campanha Bráulio - aborda diálogos entre um homem e seu órgão genital, que recebeu o nome de Bráulio. A escolha dessa denominação para a genitália foi alvo de intensos protestos, por parte daqueles que tinham esse nome e teve, como consequência, a suspensão de sua veiculação, que só foi retomada quando fizeram modificações e a genitália passou a não ter denominação alguma. Essa polêmica gerou infindáveis matérias na mídia em geral, terminando por popularizar a campanha. Ela recebeu várias críticas de vários setores da sociedade. Foi considerada uma campanha de mau gosto, que tratava a Aids como brincadeira, e que centrou a atenção muito mais na discussão do Bráulio propriamente dito do que na questão da prevenção da doença.(MARINHO. 2006 p. 8)
\end{abstract}

Alguns teóricos, porém, ligados ao estudo da prevenção do HIV/Aids, como é o caso de Nascimento (1997), consideram que reprimir a campanha Bráulio foi um equívoco, porque era um material que tratava da questão da doença de maneira informal, bem humorada e acessível, atingindo uma parcela maior da população, enquanto campanhas posteriores de tom mais sério se mostraram menos acessíveis ao grande público. Como afirma Nascimento sobre a prevenção no Brasil no final dos anos de 1990:

Independentemente do acúmulo de conhecimento acerca da doença, as campanhas oficiais sofrem visíveis avanços e retrocessos em sua capacidade de transmitir informações claras e isentas de pre- 
conceitos. A campanha mais recente, cujo slogan é Assim pega, assim não pega, é, por exemplo, menos esclarecedora que a polêmica campanha do Bráulio, veiculada pela televisão em 1996. Viva com prazer, viva o sexo seguro - tema de outra campanha - afirma positivamente o uso da camisinha. (NASClMENTO. 1997 p. 5)

Viva com prazer, viva o sexo seguro (1996)

Em https://www.youtube.com/watch?v=u3142Zy4a50

Transcrição:

- Já volto

- Oba, hoje a noite promete.

- Que é isso, cara?

- Ô chefia, eu tô loco para dar umazinha.

- Tudo bem, mas a gente tem que levar uma conversa, né? Tem que impressionar a moça.

- Deixa isso para lá, vai logo me apresentando.

- Oh, sócio, você ainda vai colocar a gente numa fria, hein!

- Ah, lá vem você de novo com esse papo de Aids.

- Sim... você é que tá com medo de afinar na hora da camisinha...

- Colé, chefia, tá me estranhando? Compra logo umas 10 aí... 10 hahahah

- Narrador: viva com prazer, viva o sexo seguro.
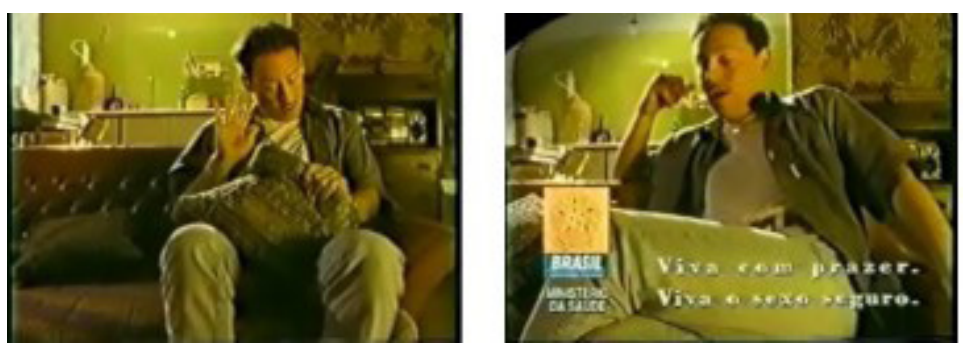

Figura 6: Imagens do comercial Bráulio

No final dos anos de 1990, no Brasil, a ênfase da mensagem preventiva se baseava quase que exclusivamente no discurso do sexo seguro, e essa tendência se manteve nos anos 2000. Pode-se dizer que houve um avanço, pois começaram a surgir tentativas de diversificação temática, ou seja, campanhas voltadas para homossexuais, profissionais da saúde, questões relacionadas à vivência com soropositivos. Porém, nem todas essas campanhas tinham grande circulação, algumas eram restritas a cartazes e folhetos de distribuição restrita, e todas utilizavam como mensagem principal o discurso do sexo seguro.

Fora do Brasil, em meados dos anos de 1990, governos e ONGs começavam a explorar o valor da divulgação irrestrita de toda a informação possível ligada à prevenção e não apenas ao reforço das mensagens de sexo seguro. A alternativa informativa tem uma excelente resposta por parte da população em geral, uma vez que esclarece dúvidas e move a responsabilidade do ato preventivo, que passa a ser não somente do indivíduo que escolhe ou não se usa o preservativo. Esse tipo de campanha visa promover uma troca, um diálogo constante entre população e governo sobre o gerenciamento individual da saúde, de forma a melhorar a resposta preventiva da população. 


\section{Conclusão}

Apesar de a política brasileira de Aids servir como referência para vários países, tendo mostrado êxito em uma série de aspectos ligados à epidemia, alguns detalhes ainda podem e devem ser trabalhados com mais cuidado. A prevenção é um bom exemplo disso. Ao contrário do protocolo de produção e distribuição de medicamentos, nossas campanhas governamentais de prevenção têm, muitas vezes, objetivos muito amplos e nem sempre estão tão atualizadas com a realidade de quem está mais suscetível a contaminação. Pensando nisso, por que não aproveitar o gancho da formação de base do designer, que o coloca constantemente diante da solução de problemas e lacunas, para pensar novos sistemas e modelos para a prevenção e gestão em saúde? O trabalho pode ser conduzido através de equipes multidisciplinares que trabalharão em parceria com profissionais de diversas áreas, como médicos, enfermeiros, psicólogos, cientistas sociais.

Infelizmente, os movimentos externos à prevenção governamental ficam limitados ao ambiente das ONGs e dos grupos de estudo e apoio. Mesmo existindo uma verba anual ou semestral que possibilita a veiculação de algumas peças de prevenção que se diferem do material distribuído pelo MS, muitas vezes esse material preventivo encontra dificuldades de circulação e não pode ser acessado pela maior parte da população.

Um caminho interessante para uma remodelação da prevenção como um todo seria pensar através da análise dos discursos ligados à Aids contidos nos meios de comunicação e nas campanhas de prevenção, para que se possa compreender os porquês da utilização na atualidade dos formatos "clássicos" da prevenção em DSTs/ Aids e, dessa forma, propor novos rumos e novas alternativas de trabalho, visando a uma melhor resposta preventiva por parte da sociedade em geral.

\section{Contato das autoras}

Simone M. Wolfgang | simone.wolfgang@terra.com.br

\section{Referências Bibliográficas}

BRASIL. Ministério da Saúde. Coordenação Nacional de DST e Aids. Sobre a epidemia da Aids no Brasil: distintas abordagens. Brasília, 1999.

CALCAGNO, L. POLÊMICA: Impedido de doar sangue. Jornal de Brasília, Brasília, 6 set. 2007.

FOUCAULT, M. História da sexualidade, volume I, Rio de Janeiro, Graal 2005.

LEMOS, J. F. O risco em cena: análise das campanhas de prevenção à AIDS da MTV Brasil. Dissertação de mestrado. Instituto de Medicina Social. Ciências Humanas e Saúde UERJ, Rio de Janeiro, 2006.

NASCIMENTO, D. R. A Face visível da Aids. In: História, Ciências, Saúde: Manguinhos. V. 1. N. 1. Rio de Janeiro, 1997.

MINISTÉRIO DA SAÚDE, Aids mediacenter campanhas. 2007. Disponível em: http://www.aids.gov.br/mediacenter

PERLONGHER, N. O que é Aids, São Paulo: Brasiliense, 1987 (A).

POLLAK, M. Os homossexuais e a AIDS, Estação Liberdade, São Paulo, 1990.

. A homossexualidade masculina, ou felicidade no ghetto. In: Sexualidades Ocidentais. Lisboa: Contexto, 1983.

RIOS, L. F. et al. Homossexualidade: produção cultural, cidadania e saúde. Rio de Janeiro: ABIA, 2005.

ROCHA, L. Sangue Contaminado. In: Isto é, Ed.1713, São Paulo, Abril, Jul 2002.

SONTAG, S.: A doença como metáfora. São Paulo: Graal, 2002.

TREVISAN, J. S. Devassos no paraíso: A homossexualidade no Brasil, da colônia à atualidade. Rio de Janeiro: Editora Record, 2004.

ESTADÃO. Mortalidade por Aids no Brasil cai 38,9\% em 11 anos. Edição 23/09/2013.

JORNAL DE BRASÍLIA. Jovem homossexual impedido de doar sangue. Edição de 14/09/2007. 